
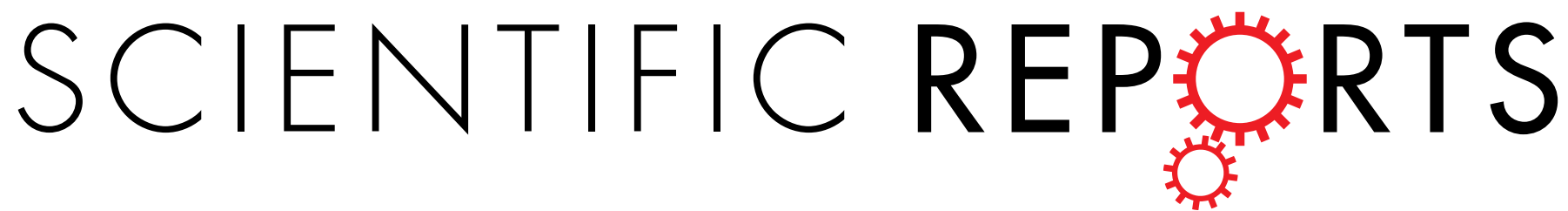

\title{
Nitrogen-doped Carbon Derived from ZIF-8 as a High-performance Metal-free Catalyst for Acetylene \\ Hydrochlorination
}

Received: 30 September 2016

Accepted: 28 November 2016

Published: 04 January 2017

\author{
Songlin Chao ${ }^{1}$, Fang Zou ${ }^{1}$, Fanfan Wan ${ }^{1}$, Xiaobin Dong ${ }^{1}$, Yanlin Wang ${ }^{1}$, Yuxuan Wang ${ }^{1}$, \\ Qingxin Guan ${ }^{1}$, Guichang Wang ${ }^{1} \&$ Wei $^{\mathrm{Li}^{1,2}}$
}

Acetylene hydrochlorination is a major industrial technology for manufacturing vinyl chloride monomer in regions with abundant coal resources; however, it is plagued by the use of mercury(II) chloride catalyst. The development of a nonmercury catalyst has been extensively explored. Herein, we report a N-doped carbon catalyst derived from ZIF-8 with both high activity and quite good stability. The acetylene conversion reached $92 \%$ and decreased slightly during a $200 \mathrm{~h}$ test at $220^{\circ} \mathrm{C}$ and atmospheric pressure. Experimental studies and theoretical calculations indicate that $\mathrm{C}$ atoms adjacent to the pyridinic $\mathrm{N}$ are the active sites, and coke deposition covering pyridinic $\mathrm{N}$ is the main reason for catalyst deactivation. The performance of those $\mathrm{N}$-doped carbons makes it possible for practical applications with further effort. Furthermore, the result also provides guidance for designing metal-free catalysts for similar reactions.

Vinyl chloride monomer (VCM) is an important commodity chemical that is used to synthesize poly(vinyl chloride) (PVC). In developing countries with abundant coal reserves, acetylene hydrochlorination is the preferred manufacturing process, using $\mathrm{HgCl}_{2}$ supported on activated carbon as the catalyst. However, the catalyst is environmentally toxic with relatively short lifetimes because the $\mathrm{HgCl}_{2}$ is apt to sublime during reaction ${ }^{1}$. Recently, about 140 countries accepted "The Minamata Convention on Mercury" and promised to reduce and eventually abolish the use of mercury by $2020^{2}$. Therefore, the development of nonmercury catalysts is the top priority for the industry in the process of acetylene hydrochlorination.

Gold catalysts have been proven to be the best replacement of mercury for this reaction ${ }^{3-5}$ and extensive work has been carried out to decrease the gold content and improve the stability of the gold catalyst ${ }^{6-9}$. Hutchings, the pioneer of gold catalyst research, has been close to achieving the commercialization of gold catalysts in collaboration with Johnson Matthey ${ }^{10}$. However, considering the limitation of the price and reserves of noble metals, development of further alternatives remains highly desirable.

The development of catalysts made with more abundant elements and even metal-free catalysts is the optimal choice for the reaction. The unique catalytic properties of carbon materials have been extensively demonstrated for a variety of reactions, and it has been proved that $\mathrm{N}$-doped carbon materials are active for acetylene hydrochlorination ${ }^{1,2}$. Bao et al. reported that a N-doped carbon derived from silicon carbide worked as a catalyst for the reaction, the acetylene conversion reaching $80 \%$ at $200{ }^{\circ} \mathrm{C}$. Theoretical simulations led to the conclusion that carbon atoms bonded with pyrrolic $\mathrm{N}$ atoms are the active sites ${ }^{2}$. Wei et al. reported that $\mathrm{N}$-doped carbon nanotubes are active for acetylene hydrochlorination and the quaternary $\mathrm{N}$ is the biggest contributing $\mathrm{N}$-containing form ${ }^{11}$. Dai et al. synthesized different $\mathrm{N}$-doped carbons through adopting $\mathrm{N}$-doping treatments on activated carbon, and the results demonstrated that pyrrolic $\mathrm{N}$ is the most important nitrogen species ${ }^{12}$. In addition, they also pointed out that pyridinic $\mathrm{N}$ at the edge of a $\mathrm{N}$-doped graphene oxide had a specific and dominant $\mathrm{HCl}$ adsorption capacity that is positive for the reaction of acetylene hydrochlorination ${ }^{13}$. Although all of this outstanding work has been explored, the role of different $\mathrm{N}$ species (pyrrolic $\mathrm{N}$, pyridinic $\mathrm{N}$, and quaternary $\mathrm{N}$ )

${ }^{1}$ College of Chemistry, Key Laboratory of Advanced Energy Materials Chemistry (Ministry of Education), Nankai University, Tianjin, 300071, China. ${ }^{2}$ Collaborative Innovation Center of Chemical Science and Engineering, Tianjin, 300071, China. Correspondence and requests for materials should be addressed to G.W. (email: wangguichang@ nankai.edu.cn) orW.L. (email: weili@nankai.edu.cn) 
in active sites is still under debate $\mathrm{e}^{11,13,14}$, and the practical applications of $\mathrm{N}$-doped carbon materials are limited by relatively low conversion, poor stability, or low production capacity ${ }^{2,11,13}$.

Herein, we report a N-doped carbon catalyst for acetylene hydrochlorination with both high activity and quite good stability (the acetylene conversion reached $92 \%$ and decreased slightly during a $200 \mathrm{~h}$ test at $220^{\circ} \mathrm{C}$, atmospheric pressure, and $1.4 \mathrm{~mL} \mathrm{~g}^{-1} \mathrm{~min}^{-1}$ of $\mathrm{C}_{2} \mathrm{H}_{2}$, corresponding to a space velocity of $30 \mathrm{~h}^{-1}$ based on the catalyst volume). Experimental studies and theoretical calculations indicate that $\mathrm{C}$ atoms adjacent to the pyridinic $\mathrm{N}$ are the active sites, and coke deposition covering pyridinic $\mathrm{N}$ is the main reason for catalyst deactivation.

\section{Results}

For $\mathrm{N}$-doped carbon materials used as catalysts, large specific surface and high dispersion of $\mathrm{N}$ species are crucial factors affecting catalyst activity and stability. Based on this consideration, the ZIF-8 is a good candidate to synthesize $\mathrm{N}$-doped carbons directly upon carbonization because of the multiple advantages of ZIF-8-large surface area, regular structure, and a high $\mathrm{N}$ content ${ }^{15-18}$. Initially, ZIF-8 was synthesized in methanol at room temperature (for details see the Supplementary Information). The synthesis route was selected because the synthesis reaction could be promoted by molecular interactions between the reagents and the solvent with hydrogen-bond donation ability, which could improve textural properties and produce a smaller particle size of ZIF- $8^{19,20}$. According to the results of X-ray diffraction (XRD), scanning electron microscope (SEM), transmission electron microscope (TEM), and nitrogen adsorption/desorption measurements shown in Fig. 1a and b, the prepared ZIF-8 has pure phases, ordered crystalline shapes with a particle size of about 200 to $300 \mathrm{~nm}$, and abundant pore structures with the surface area up to $2074 \mathrm{~m}^{2} \mathrm{~g}^{-1}$.

Effect of calcination temperature on materials' morphology and catalytic activity. To investigate the influence of calcining temperature on carbon materials, ZIF-8 was carbonized at different temperatures $\left(600,800,1000\right.$, and $\left.1100^{\circ} \mathrm{C}\right)$ under flowing $\mathrm{N}_{2}$ to obtain $\mathrm{N}$-doped carbons with different $\mathrm{N}$-species content and texture properties ${ }^{21}$. The choice of temperature is based on the result of thermogravimetric analysis (TGA) (See Supplementary Fig. S1) that the mass loss of ZIF-8 mainly occurs after heating to $600^{\circ} \mathrm{C}$. It is important to emphasize that the ZIF- 8 was kept for at least $1 \mathrm{~h}$ at $300^{\circ} \mathrm{C}$ for better properties of the carbon materials (See detailed process in the Supplementary Information). The pore texture information and SEM images of obtained N-doped carbons (C-600, C-800, C-1000, and C-1100) are shown in Fig. 1c-f, respectively. Compared with ZIF-8, the obtained carbons exhibit a significant decrease in surface area, and the average pore size shifts from 0.61 to $0.40 \mathrm{~nm}$ or so. This is because the framework of ZIF- 8 has collapsed at the carbonization temperatures, and the porosity of $\mathrm{N}$-doped carbons comes from cracks in the framework and the evaporation of $\mathrm{Zn}$ metal during pyrol$\mathrm{ysis}^{16}$. In addition, washing with hydrochloric acid after the carbonization process removed residual $\mathrm{Zn}$ in those carbons and provided additional pore structure at the same time.

The set of $\mathrm{N}$-doped carbons $(0.3 \mathrm{~g})$ was tested for acetylene hydrochlorination at $220^{\circ} \mathrm{C}$ and an acetylene space velocity of $4.6 \mathrm{~mL} \mathrm{~g}^{-1} \mathrm{~min}^{-1}$ (For details see the Supplementary Information). The results are shown in Fig. 1g. It should be mentioned that catalytic selectivity of all the catalysts tested in this study is virtually $100 \%$. The initial acetylene conversion of the $\mathrm{N}$-doped carbons has a positive correlation with the carbonization temperature, and the conversion of C-600, C- $800, \mathrm{C}-1000$, and C-1100 is ca. $23 \%, 35 \%, 65 \%$, and $75 \%$, respectively. Based on the data shown in Fig. 1c-f, different catalytic activity mainly comes from the difference in surface area and pore structure. Furthermore, it has been proved that doping $\mathrm{N}$ species play the main role in forming the active sites for acetylene hydrochlorination ${ }^{1,2}$. To investigate the effects of $\mathrm{N}$ species on catalytic activity, X-ray photoelectron spectroscopy (XPS) analyses of fresh and used N-doped carbon catalysts were carried out. According to the bonding state of $\mathrm{N}$ atoms, the $\mathrm{N} 1 \mathrm{~s}$ spectra were deconvolved into three individual component peaks: pyridinic $\mathrm{N}(398.3-399.8 \mathrm{eV})$, pyrrolic $\mathrm{N}(400.1-400.5 \mathrm{eV})$, and quaternary $\mathrm{N}(401-402 \mathrm{eV})^{2,11,17,22}$. The statistics of the change of different $\mathrm{N}$-doped carbons is summarized in Fig. $1 \mathrm{~h}$, and see the detailed curve fitting in Supplementary Fig. S2. According to the results of XPS, total N content of the set of N-doped carbons is $20.47 \%$, $13.19 \%, 4.98 \%$, and $2.78 \%$, respectively. The decrease of $\mathrm{N}$ content with the increase of temperature is because nitrogen in the ZIF-8 is carried off in the airflow when the framework is destroyed at high temperature. According to the histogram, the percentage of pyridinic $\mathrm{N}$ decreased, whereas the pyrrolic and quaternary $\mathrm{N}$ increased after reaction. Based on the report that coke formation covering the active sites was the main reason for deactivation ${ }^{13}$, it seems that for the $\mathrm{N}$-doped carbon catalysts, the deactivation was caused by coke deposition on pyridinic $\mathrm{N}$, which is responsible for creation of the active site. To sum up, the $\mathrm{N}$-doped carbons obtained at elevated temperature have low pyridinic $\mathrm{N}$ content but high reaction conversion may be because carbons calcined under elevated temperatures have a more microcrystalline structure and higher specific surface area, which could provide more defects and effective $\mathrm{N}$ species for acetylene hydrochlorination (For more discussion see the Supplementary Inf ormation Figs S3 and S4).

Long-term stability test of the improved catalyst and study of the deactivation mechanism. To improve the catalytic activity further, ZIF- 8 was calcined under an $\mathrm{NH}_{3}$ atmosphere because $\mathrm{NH}_{3}$ could expand the micropore size-distributions and increase the surface defects ${ }^{23}$. In addition, to make the material synthesis more efficient and convenient, ZIF-8 was prepared using a solid-state synthesis, in which $\mathrm{ZnO}$ was mixed with ligands and heated directly to yield ZIF- $8^{16,20}$. Although there are some differences in the crystal size and crystallinity of ZIF-8 synthesized via different routes (See Supplementary Fig. S5), the N-doped carbons calcined under $\mathrm{N}_{2}$ atmosphere show consistent catalytic activity. The ZIF-8 synthesized using the solid-state method was calcined at $1000^{\circ} \mathrm{C}$ under $\mathrm{N}_{2}$ and $\mathrm{NH}_{3}$ atmospheres, and the obtained carbons (referred to as $\mathrm{C}-\mathrm{N}_{2}, \mathrm{C}-\mathrm{NH}_{3}$ ) were tested for long-term stability for acetylene hydrochlorination. C- $\mathrm{N}_{2}(1 \mathrm{~g}$, ca. $2.6 \mathrm{~mL})$ and $\mathrm{C}-\mathrm{NH}_{3}(1 \mathrm{~g}$, ca. $2.8 \mathrm{~mL})$ were tested in a fixed-bed microreactor with the $\mathrm{HCl}$ at $1.7 \mathrm{~mL} \mathrm{~min}^{-1}$ and $\mathrm{C}_{2} \mathrm{H}_{2}$ at $1.4 \mathrm{~mL} \mathrm{~min}^{-1}$, corresponding to a space velocity of about $30 \mathrm{~h}^{-1}$. 

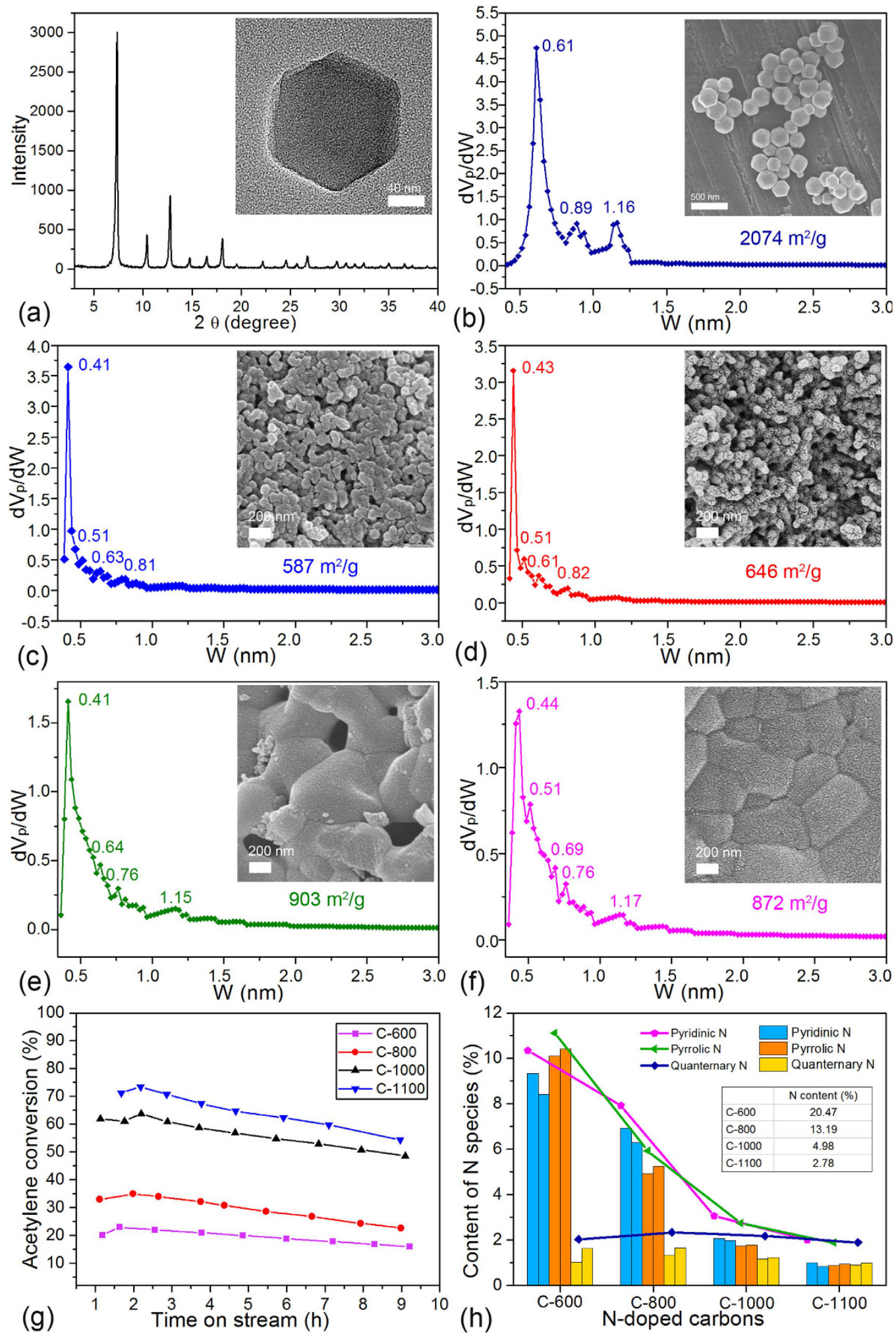

Figure 1. (a) XRD pattern and TEM image of ZIF-8. (b-f) Pore information and SEM images of ZIF-8, C-600, C-800, C-1000 and C-1100. (g) Acetylene conversion by N-doped carbon. Reaction conditions: temperature $=220^{\circ} \mathrm{C}$, a space velocity of $\mathrm{C}_{2} \mathrm{H}_{2}=4.7 \mathrm{~mL} \mathrm{~g}^{-1} \mathrm{~min}^{-1}$, feed volume ratio between $\mathrm{HCl}$ and $\mathrm{C}_{2} \mathrm{H}_{2}=1.2$. Due to the different bulk density, the corresponding $\mathrm{C}_{2} \mathrm{H}_{2}$ gas hourly space velocity (GHSV) of C-600, C-800, C-1000 and C-1100 is: $129 \mathrm{~h}^{-1}, 112 \mathrm{~h}^{-1}, 105 \mathrm{~h}^{-1}$ and $87 \mathrm{~h}^{-1}$, respectively. (h) $\mathrm{N}$ content analysis base on XPS. (1) N content in the table comes from fresh $\mathrm{N}$-doped carbons. (2) The broken line shows content change trend of the specific $\mathrm{N}$ species with the temperature increases. (3) Histograms exhibit content of specific $\mathrm{N}$ specie in different $\mathrm{N}$-doped carbons, and for the adjacent two same color pillars, the left represent $\mathrm{N}$ specie content of fresh carbons meanwhile the right represent that of used carbons. 

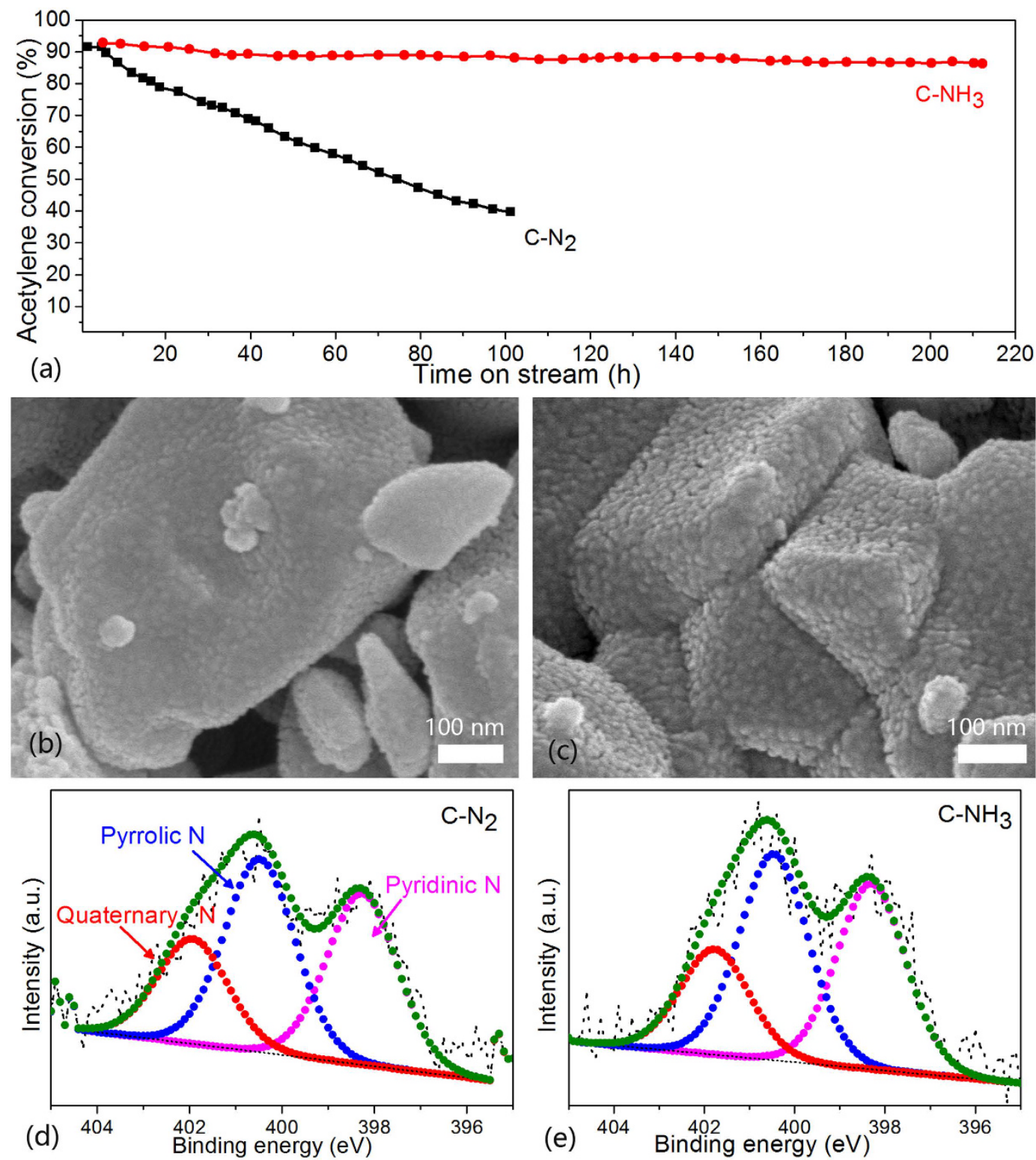

Figure 2. (a) Acetylene conversion by $\mathrm{N}$-doped carbon. Reaction conditions: temperature $=220^{\circ} \mathrm{C}$, a space velocity of $\mathrm{C}_{2} \mathrm{H}_{2}=1.4 \mathrm{~mL} \mathrm{~g}^{-1} \mathrm{~min}^{-1}$, feed volume ratio between $\mathrm{HCl}$ and $\mathrm{C}_{2} \mathrm{H}_{2}=1.2$. (b-d) SEM images of C- $\mathrm{N}_{2}$ and $\mathrm{C}-\mathrm{NH}_{3}$. (e) and (f) $\mathrm{N} 1 \mathrm{~s}$ XPS of C-N $\mathrm{N}_{2}$ and C-NH .

Obviously, C- $\mathrm{NH}_{3}$ exhibits high acetylene conversion of about $92 \%$ and a rather good stability with the conversion only decreasing slightly during a $200 \mathrm{~h}$ test, whereas the $\mathrm{C}-\mathrm{N}_{2}$ shows basically the same initial activity but poor stability, as demonstrated in Fig. 2a. For N-doped carbon catalysts, pore structure and the active $\mathrm{N}$ species are the main factors affecting catalyst activity. According to Fig. $2 b$ and c, the $\mathrm{C}-\mathrm{NH}_{3}$ has a larger specific surface area $\left(1166.6 \mathrm{~m}^{2} \mathrm{~g}^{-1}\right)$ than $\mathrm{C}-\mathrm{N}_{2}\left(875.5 \mathrm{~m}^{2} \mathrm{~g}^{-1}\right)$, which mainly comes from the greater micropore structure. From the SEM pictures, $\mathrm{C}-\mathrm{NH}_{3}$ also reveals more abundant texture structure, which may be from the activation of ammonia ${ }^{24}$. On the other hand, $\mathrm{C}-\mathrm{NH}_{3}$ and $\mathrm{C}-\mathrm{N}_{2}$ have basically the same $\mathrm{N}$ content $\left(6.28 \%\right.$ for $\mathrm{C}-\mathrm{N}_{2}$ and $4.59 \%$ for $\mathrm{C}-\mathrm{NH}_{3}$ according to the results of XPS) and similar N-species proportion, as shown in Fig. $2 \mathrm{~d}$ and e. In sum, $\mathrm{C}-\mathrm{NH}_{3}$ has better catalytic stability than C- $\mathrm{N}_{2}$ as it has a larger surface area and similar $\mathrm{N}$ content. However, it is still not clear what the decisive factor for the difference in stability is.

The loss of active component is the main reason for catalyst deactivation in industrial use of mercury catalyst. However, the $\mathrm{N}$-doped carbon catalyst obtained by calcination at elevated temperatures has a more stable structure compared with the supported mercury catalyst. The results of element analysis $\left(6.35 \%\right.$ for $\mathrm{C}-\mathrm{N}_{2}$ and $4.03 \%$ for $\mathrm{C}-\mathrm{NH}_{3}, 5.89 \%$ for the used $\mathrm{C}-\mathrm{N}_{2}$ and $3.85 \%$ for the used $\mathrm{C}-\mathrm{NH}_{3}$ ) reveals that the $\mathrm{N}$ contents of $\mathrm{C}-\mathrm{N}_{2}$ and $\mathrm{C}-\mathrm{NH}_{3}$ have a slight change after the long-term test. And the reducing of $\mathrm{N}$ contents should mainly be caused by the carbon deposition increasing the quality of the samples rather than by the physical loss. 

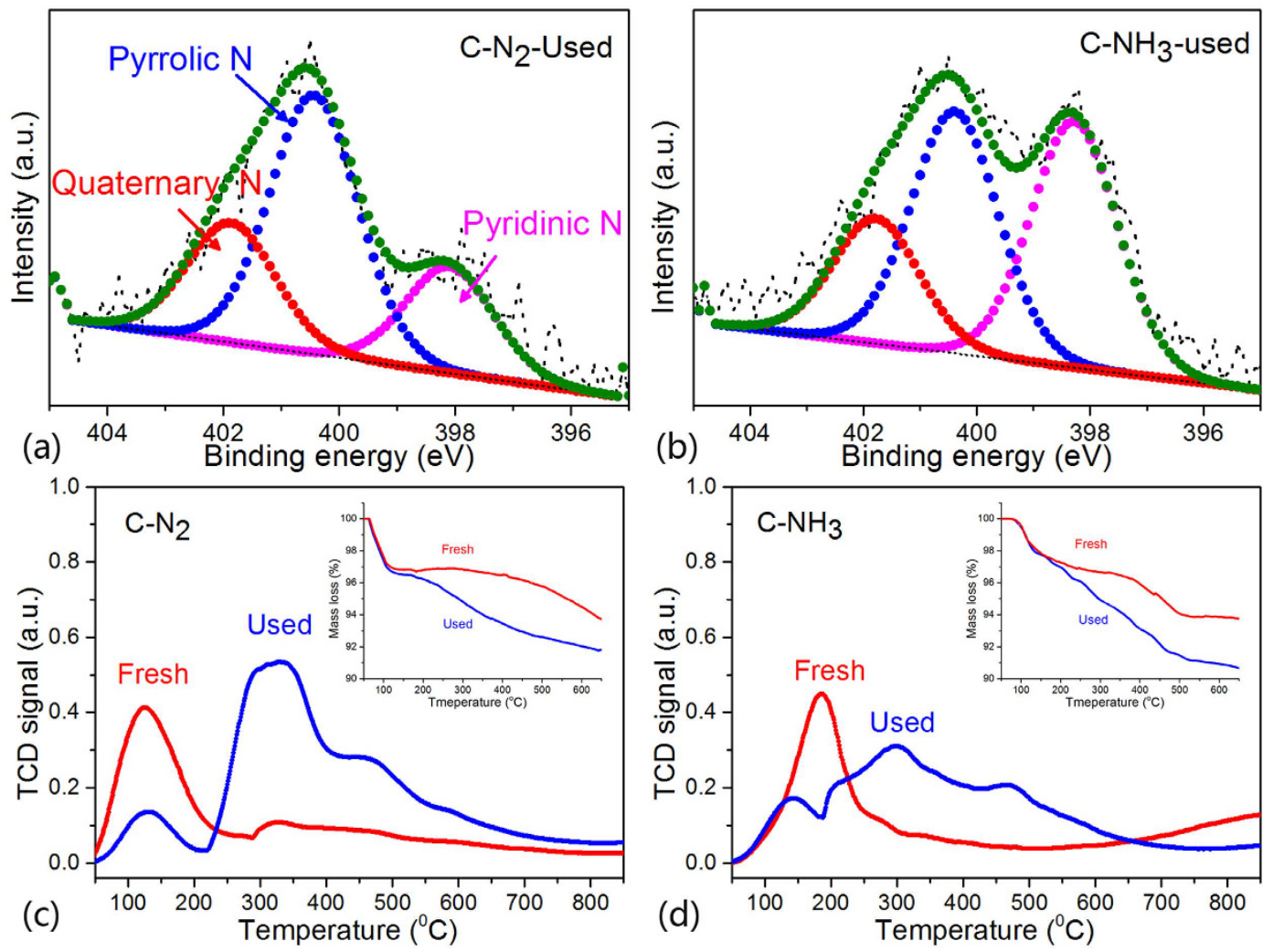

Figure 3. (a) and (b) N $1 \mathrm{~s}$ XPS of used $\mathrm{C}-\mathrm{N}_{2}$ and $\mathrm{C}-\mathrm{NH}_{3}$. (c) and (d) $\mathrm{C}_{2} \mathrm{H}_{2}-\mathrm{TPD}$ and (b) TG analysis of used $\mathrm{C}-\mathrm{N}_{2}$ and $\mathrm{C}-\mathrm{NH}_{3}$.

To understand the difference further, the $\mathrm{C}-\mathrm{N}_{2}$ and $\mathrm{C}-\mathrm{NH}_{3}$ were characterized with XPS, TGA, and temperature-programmed desorption (TPD) using $\mathrm{C}_{2} \mathrm{H}_{2}$ as the probe. It is worth noting that the proportion of pyridinic $\mathrm{N}$ in C- $\mathrm{N}_{2}$ reduced from $36.6 \%$ to $21.9 \%$ after a $100 \mathrm{~h}$ test; meanwhile, the pyridinic $\mathrm{N}$ ratio of C- $\mathrm{NH}_{3}$ basically remained unchanged after the $200 \mathrm{~h}$ test (Fig. 3a and b). It is consistent with the statistical result shown in Fig. 1h, which means that deactivation was caused by coke deposition on pyridinic $\mathrm{N}$, which is responsible for creation of the active site. According to the $\mathrm{C}_{2} \mathrm{H}_{2}$ TPD of fresh C- $\mathrm{N}_{2}$ and $\mathrm{C}-\mathrm{NH}_{3}$ (Fig. $3 \mathrm{c}$ and d), there is only one desorption peak below $200^{\circ} \mathrm{C}$, which represents the adsorption and activation of $\mathrm{C}_{2} \mathrm{H}_{2}{ }^{25}$. However, there is another peak between 200 and $500^{\circ} \mathrm{C}$ for the catalysts used, and the peak area below $200^{\circ} \mathrm{C}$ is lower than that of the fresh catalyst. The decrease of peak area below $200^{\circ} \mathrm{C}$ represents the reduction of the ability to adsorb and activate $\mathrm{C}_{2} \mathrm{H}_{2}$, which may be caused by covering of the active sites. The peak between 200 and $500{ }^{\circ} \mathrm{C}$ should come from the decomposition of coke deposition combining with the results of TGA in Fig. $3 \mathrm{c}$ and d. Combined with the results of XPS, it might be concluded that coverage of the pyridinic $\mathrm{N}$ is the reason for catalyst deactivation.

Two points should be noted: the results of $\mathrm{C}_{2} \mathrm{H}_{2}$ TPD show that the peak between 200 and $500{ }^{\circ} \mathrm{C}$ of used catalyst could be convolved into multiple desorption peaks and the surface area is far larger than the area of the peak below $200^{\circ} \mathrm{C}$. This may be because the coke deposition is a polymer ${ }^{10}$, which would decompose giving more gaseous product than the adsorbed $\mathrm{C}_{2} \mathrm{H}_{2}$ under the TPD process. In addition, the nitrogen adsorption data that the surface area of C- $\mathrm{N}_{2}$ decreases from 875.5 to $264.5 \mathrm{~m}^{2} \mathrm{~g}^{-1}$ after catalytic reaction while the surface area of $\mathrm{C}-\mathrm{NH}_{3}$ decreases from 1166.6 to $617.0 \mathrm{~m}^{2} \mathrm{~g}^{-1}$ also demonstrated that coke deposition is the main reason for catalyst deactivation. However, it is still unclear why the $\mathrm{C}-\mathrm{N}_{2}$ and $\mathrm{C}-\mathrm{NH}_{3}$ have a small difference in surface area and pyridinic $\mathrm{N}$ content, but huge difference in catalytic stability.

Reaction mechanism studied by density functional theory (DFT). DFT calculations were carried out for further understanding of the difference in catalytic stability. Both theory and experiments indicate that carbon atoms bound to $\mathrm{N}$ are the active sites in $\mathrm{N}$-doped carbon ${ }^{1,2,11,22}$. Thus, various structure models of pyridinic $\mathrm{N}$ have been inspected. Effective models and two possible catalytic pathways are shown in Fig. 4a,b and c. The first step in the reaction is most likely to be the addition of $\mathrm{C}_{2} \mathrm{H}_{2}$ to the potential active sites (Fig. $4 \mathrm{a}$, sites 1 and 2$)$ and the corresponding data are shown in Fig. $4 \mathrm{c}(-0.27 \mathrm{eV}$ and $-0.70 \mathrm{eV}$ correspond to sites 1 and 2 , respectively). Subsequently, $\mathrm{HCl}$ approaches the catalyst with dissociative adsorption energies of $-0.53 \mathrm{eV}$ and $-0.94 \mathrm{eV}$. The reactants need to surmount an additional barrier $(1.40 \mathrm{eV}$ and $1.57 \mathrm{eV}$, respectively) to achieve the transition state structures, and then a $\mathrm{CH}_{2} \mathrm{CHCl}$ molecule is formed with adsorption energies of $-1.14 \mathrm{eV}$ for site 1 and $-1.40 \mathrm{eV}$ for site 2 . Finally, the formed $\mathrm{CH}_{2} \mathrm{CHCl}$ escapes from the catalyst and the product is obtained. Comparing the different reaction processes, the pathway corresponding to site 1 with a barrier of $1.40 \mathrm{eV}$ is the most favorable reaction route on $\mathrm{N}$-doped carbon for acetylene hydrochlorination. For the structure model of 


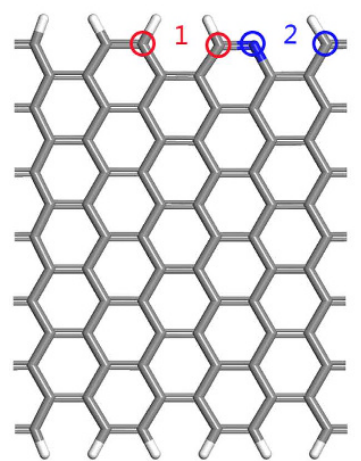

(a)
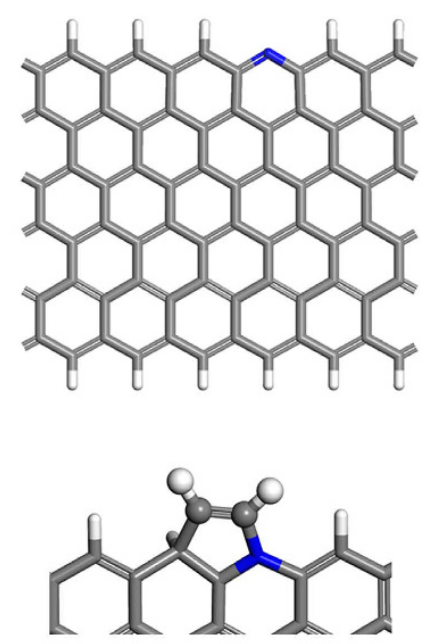

$E_{a}=-1.97 \mathrm{eV}$

(d)

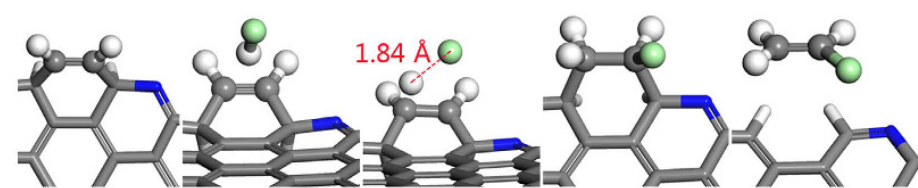

(b)

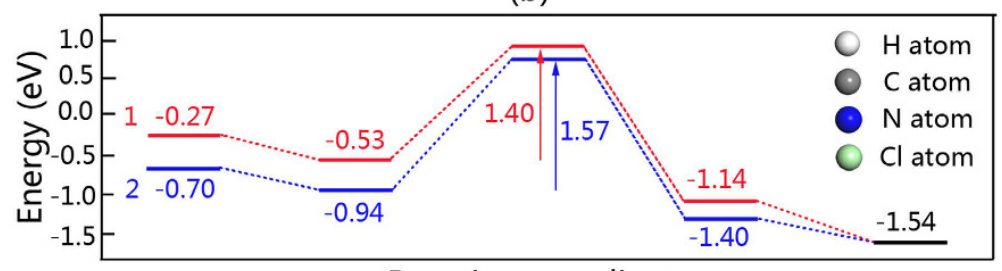

Reaction coordinate

(c)

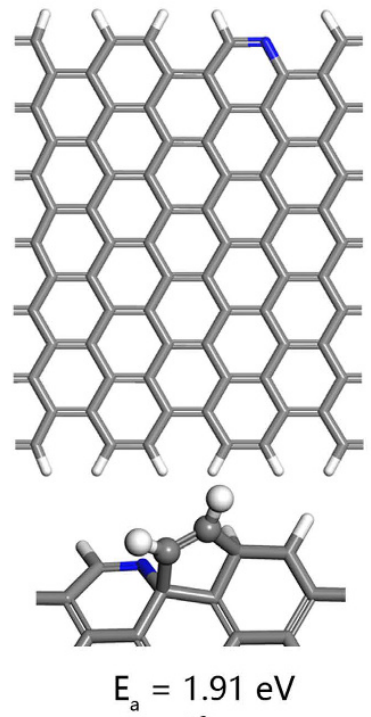

(f)

Figure 4. DFT calculations on the reaction mechanism. (a) Structure models with pyridinic N, with the blue representing $\mathrm{N}$ atoms, the grey representing $\mathrm{C}$ atoms, the white representing $\mathrm{H}$ atoms. Sites 1 denotes two neighbor $\mathrm{C}$ atoms; sites 2 stands for pyridinic $\mathrm{N}$ atom and neighbor $\mathrm{C}$ atom. (b) The possible catalytic pathway basing on sites 1. (c) Reaction energy profile on sites 1 and 2 from DFT calculations. (d-f) Other structure models of pyridinic $\mathrm{N}$.

pyridinic $\mathrm{N}$ shown in Fig. 4d, the energy of acetylene adsorption on zigzag edges of $\mathrm{N}$-doped carbon is $-1.97 \mathrm{eV}$. This is a very stable configuration, which will make vinyl chloride stripping difficult. Polymerization of $\mathrm{C}_{2} \mathrm{H}_{2}$ or VCM may be caused in this type of site. This may be the reason for coke deposition and catalyst deactivation. For structures shown in Fig. $4 \mathrm{e}$ and $\mathrm{f}$, it is hard to adsorb acetylene with energies of $0.94 \mathrm{eV}$ and $1.91 \mathrm{eV}$. Those may be some of the reasons why some $\mathrm{N}$-doped carbons with high pyridinic $\mathrm{N}$ content show low reaction conversion.

\section{Discussion}

Combining with the DFT calculations and the experimental data, it seems large enough surface area and effectively pyridinic $\mathrm{N}$ provide a similar catalytic activity for $\mathrm{C}-\mathrm{N}_{2}$ and $\mathrm{C}-\mathrm{NH}_{3}$. And the difference in pyridinic $\mathrm{N}$ structures make C- $\mathrm{N}_{2}$ easier to cause coke deposition than $\mathrm{C}-\mathrm{NH}_{3}$, which is the reason caused the differences between the stability of those two $\mathrm{N}$-doped carbon catalysts. However, there is no clear evidence to prove the hypothesis. It need more sophisticated model catalyst and higher precision of spectral characterization to distinguish the certain pyridinic $\mathrm{N}$ structures, and then determine the relationship between the certain pyridinic $\mathrm{N}$ structure and the catalytic activity. However, it a challenge to control the generation of certain $\mathrm{N}$ structures.

In summary, it has been demonstrated that the synthesis of N-doped carbon using ZIF-8 as the precursor is a convenient and feasible strategy for preparing highly efficient catalysts for acetylene hydrochlorination. The $\mathrm{N}$-doped carbon derived from ZIF- 8 calcined at $1000^{\circ} \mathrm{C}$ exhibits high acetylene conversion of ca. $92 \%$ and outstanding stability during a $200 \mathrm{~h}$ test at $220^{\circ} \mathrm{C}$, and a space velocity of $30 \mathrm{~h}^{-1}$. The results of analysis on deactivation of the catalyst indicate that coverage of the pyridinic $\mathrm{N}$ is the main reason for catalyst deactivation. The DFT showed that only the specific pyridinic N structure is effective for creating active sites; meanwhile, other structures can produce coke deposits easily. In-depth studies of ZIF-derived carbon for practical application to acetylene hydrochlorination are in progress in our group. 


\section{References}

1. Zhu, M. Y. et al. Development of a Heterogeneous Non-Mercury Catalyst for Acetylene Hydrochlorination. Acs Catalysis 5, 5306-5316 (2015).

2. Li, X. et al. Silicon carbide-derived carbon nanocomposite as a substitute for mercury in the catalytic hydrochlorination of acetylene. Nature communications 5, 3688-3688 (2014).

3. Hutchings, G. Vapor phase hydrochlorination of acetylene: Correlation of catalytic activity of supported metal chloride catalysts. J. Catal. 96, 292-295 (1985).

4. Nkosi, B., Coville, N. J. \& Hutchings, G. J. Vapour phase hydrochlorination of acetylene with group VIII and IB metal chloride catalysts. Applied Catalysis 43, 33-39 (1988).

5. Conte, M. et al. Hydrochlorination of acetylene using supported bimetallic Au-based catalysts. J. Catal. 257, 190-198, doi: 10.1016/j. jcat.2008.04.024 (2008).

6. Zhou, K. et al. A low content Au-based catalyst for hydrochlorination of $\mathrm{C} 2 \mathrm{H} 2$ and its industrial scale-up for future PVC processes. Green Chemistry 17, 356-364 (2015).

7. Zhao, J. et al. Activated-Carbon-Supported Gold-Cesium(I) as Highly Effective Catalysts for Hydrochlorination of Acetylene to Vinyl Chloride. Chempluschem 80, 196-201 (2015).

8. Conte, M. et al. Hydrochlorination of acetylene using supported bimetallic Au-based catalysts (vol 257, pg 190, 2008). J. Catal. 266, 164-164 (2009).

9. Huang, C., Zhu, M., Kang, L. \& Dai, B. A novel high-stability Au(III)/Schiff-based catalyst for acetylene hydrochlorination reaction. Catal. Commun. 54, 61-65 (2014).

10. Johnston, P., Carthey, N. \& Hutchings, G. J. Discovery, Development, and Commercialization of Gold Catalysts for Acetylene Hydrochlorination. J. Am. Chem. Soc. 137, 14548-14557 (2015).

11. Zhou, K. et al. The Catalytic Pathways of Hydrohalogenation over Metal-Free Nitrogen-Doped Carbon Nanotubes. ChemSusChem (2014).

12. Zhang, C., Kang, L., Zhu, M. \& Dai, B. Nitrogen-doped active carbon as a metal-free catalyst for acetylene hydrochlorination. Rsc Advances 5, 7461-7468 (2015).

13. Dai, B., Chen, K., Wang, Y., Kang, L. \& Zhu, M. Boron and Nitrogen Doping in Graphene for the Catalysis of Acetylene Hydrochlorination. ACS Catalysis 5, 2541-2547 (2015).

14. Li, X., Wang, Y., Kang, L., Zhu, M. \& Dai, B. A novel, non-metallic graphitic carbon nitride catalyst for acetylene hydrochlorination. J. Catal. 311, 288-294 (2014).

15. Zhong, H. X. et al. ZIF-8 Derived Graphene-Based Nitrogen-Doped Porous Carbon Sheets as Highly Efficient and Durable Oxygen Reduction Electrocatalysts. Angewandte Chemie-International Edition 53, 14235-14239 (2014).

16. Zhao, D. et al. Highly Efficient Non-Precious Metal Electrocatalysts Prepared from One-Pot Synthesized Zeolitic Imidazolate Frameworks. Adv. Mater. 26, 1093-1097 (2014).

17. Zhang, P. et al. ZIF-derived in situ nitrogen-doped porous carbons as efficient metal-free electrocatalysts for oxygen reduction reaction. Energy \& Environmental Science 7, 442-450 (2014).

18. Park, K. S. et al. Exceptional chemical and thermal stability of zeolitic imidazolate frameworks. Proceedings of the National Academy of Sciences 103, 10186-10191 (2006).

19. Zhang, L. J. et al. Highly graphitized nitrogen-doped porous carbon nanopolyhedra derived from ZIF-8 nanocrystals as efficient electrocatalysts for oxygen reduction reactions. Nanoscale 6, 6590-6602 (2014).

20. Lee, Y.-R. et al. ZIF-8: A comparison of synthesis methods. Chem. Eng. J. 271, 276-280 (2015).

21. Arrigo, R., Haevecker, M., Schloegl, R. \& Su, D. S. Dynamic surface rearrangement and thermal stability of nitrogen functional groups on carbon nanotubes. Chem. Commun. 4891-4893 (2008).

22. Guo, D. et al. Active sites of nitrogen-doped carbon materials for oxygen reduction reaction clarified using model catalysts. Science 351, 361-365 (2016).

23. Wang, D. W. et al. Nitrogen-Doped Carbon Monolith for Alkaline Supercapacitors and Understanding Nitrogen-Induced Redox Transitions. Chemistry-a European Journal 18, 5345-5351 (2012).

24. Świetlik, U., Grzyb, B., Torchała, K., Gryglewicz, G. \& Machnikowski, J. High temperature ammonia treatment of pitch particulates and fibers for nitrogen enriched microporous carbons. Fuel Process. Technol. 119, 211-217 (2014).

25. Chao, S., Guan, Q. \& Li, W. Study of the active site for acetylene hydrochlorination in AuCl3/C catalysts. J. Catal. 330, 273-279 (2015).

\section{Acknowledgements}

This work was financially supported by the NSFC (21376123, U140329321603107), MOE (IRT-13R30 and 113016A), and the Research Fund for 111 Project (B12015).

\section{Author Contributions}

As for the authors, Songlin Chao and Fang Zou contributed equally in designing and completing the main experiments, and they completed the writing of the manuscript together. Fanfan Wan was responsible for the DFT calculation. Xiaobin Dong, Yanlin Wang, Yuxuan Wang and Qingxin Guan were responsible for specific experimental operations. Wei Li and Guichang Wang were corresponding authors in charge of supervising the work.

\section{Additional Information}

Supplementary information accompanies this paper at http://www.nature.com/srep

Competing financial interests: The authors declare no competing financial interests.

How to cite this article: Chao, S. et al. Nitrogen-doped Carbon Derived from ZIF- 8 as a High-performance Metal-free Catalyst for Acetylene Hydrochlorination. Sci. Rep. 7, 39789; doi: 10.1038/srep39789 (2017).

Publisher's note: Springer Nature remains neutral with regard to jurisdictional claims in published maps and institutional affiliations.

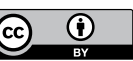

This work is licensed under a Creative Commons Attribution 4.0 International License. The images or other third party material in this article are included in the article's Creative Commons license, unless indicated otherwise in the credit line; if the material is not included under the Creative Commons license, users will need to obtain permission from the license holder to reproduce the material. To view a copy of this license, visit http://creativecommons.org/licenses/by/4.0/

(C) The Author(s) 2017 